\title{
THE INTELLIGENCE QUOTIENT FROM TWO VIEWPOINTS
}

\author{
BY W. T. RooT \\ UNIVERSITY OF PITTSBURGH
}

Recent literature has revealed considerable difference of opinion concerning le constaney, value ancinterpietation of the $I Q$ Much of the discussion arises from two distinct practical situations which educators and psychologists have to meet It is the purpose of this paper to analyze these attitudes arising therefrom and apply a little psychology to the psychologist. The writer feels that much of this difference of opinion is largely due to bias arising from the direction of attention to one's limited interests, and is more apparent than real.

The rew of the psucho-statzstzcian and the educutional admiristiator The psychologist hunting for statistical tiends and the administrator seeking approximations find themselves in accoid in the interpretation of the $I Q$ They find that for the vely large majority of the subjects tested the $I$. $Q$ remains constant or nearly so-sufiricient for all practical purposes For example, if a school administrator wishes to reorganize his school, let us say the Juinor High, into three sections for each grade, and has the list of pupils below $80 \mathrm{I} \mathrm{Q}$, from $80 \mathrm{I} \mathrm{Q}$ to $100 \mathrm{I} \mathrm{Q}$., and 100 to the uppel limit, he can safely count on these groups remaining constant for rough administıatıve purposes. There will be a few shiftings to be sure

But the very weight of statistical trends and the serviceability of tests in a broad administrative way lead the practical school man who has gone $m$ for tests to vew the I Q as very "reliable," and he feels considerable impatience wath any dwelling upon and anal$y$ sis of the exceptional cases, or anything that detracts from the simplicity of the intellectual and administrative schema. Immediate practical usability in a large way dommates his thinking and action, while his dally duties accentuate this riew Again, teachers in certain sections are divided into testers and antitesters, and one may safely assume that such "all-or-none' conditions of acceptance rest on emotional belief akin to religious fervor which is likely to supplant detached scientific attitude.

Turnmg now to the psycho-statistician's view and the organization of the Binet tests. The Stanford Revision is so constiucted that in an unbiased sampling of children the median chronologica! age equals the median mental age year by year This unbiased sampling assumes of course that we have "medianed" all factors; physical, health, hereditary, environmental, and so on. Roughly the data make a symetrical curve, year by yeal, with an increasing spread of the scatter-distribution of the mental performance as we ascend the chronological age scale. It is interesting and lends 
force to the constancy of 1 . Q. argument, that the mcreasing scatter fits nucely just what one would have if each variate were plotted as having a constant ratio between mental and chronological age. The data year by year or as a whole may be treated as conforming to the normal curve ${ }^{1}$ (although this may not prove to be true, ) but at least it suffices for all immediate practical purposes.

Let us now assume an unbiased sampling of the child population Will this group from year to year give a distribution similai to that obtained in the Stanford Revision (applying the usual statistical tests of central tendency and variability-median, $P$. E.'s, etc?) Will the mental-age rank order and the I Q remain relatively constant for each of the variates?

Statistical prediction depends upon the causal factors remaining constant for the mass of the variates in question. Turning now to our group under consideration the factors of hereditary equipment which are basic will in the main remain the same, and whlle there will be some ups and downs, in the vast majority of cases the envrommental setting will contmue roughly constant. The mores, culture, deals, aims and habits of thought will continue relatively unchanged for the different family groups The domunant cultural change will be provided by the public schools, but considering masses, this element is injected at the same time for the same duration as in the statistical sampling (the Stanford Revision ) The burden of proof is with him who would predict that our three year group will depart serously from the established norms as they advance year by year. Farthermore, the constancy of the factors producing intelligent behavior will maintain for the mass of the subjects considered individually, which in turn would make for progressive constancy of mental age rank-ordel and constancy of 1 . Q. It is highly improbable that any pronounced hereditary or environmental change will affect the masses in any brief period of time but it is equally true that conspicuous changes in environment, sensory deprivation or restoration, systemic conditions, emotional complexes, disease, and so on, can and do take place in the indrvidual case

The veu of the clinical psichologist So much for the ninetyand-nune that determine the character of distributions, stabilize medians, permit the psycho-statistician to indulge in scientific prophecy, and allow the educational administrator to convince his board that he has unusual clarvoyant powers. The viriter confesses that his sympathies are at times with those who must meet the one, two or three that lie outside the fold of statistical con-

"Roughly symmetrical" is ucually all that can be said of the data 
formity Psychological chincs are likely to get this residue of atypical cases, consequently the clinical psychologist is less likely to be impressed by statistical trends than the educational administrator, and gets little solace from the average constancy of the I. Q. when he deals with a peculiarly exasperating subject.

Thus can best be illustrated with cases Case $M$ has had succes>reely I Q 's of $93,79,98$, and 89 The detalls of the case are too long to give here, suffice it to say that the same exammer adminisstered the Stanford Revision at each examination The subject possesses no marked peculiarities except the mability to learn to read. This inability is in the nature of almost complete fallure to acquire an appieciation of phonic values Practically all words are sight words to this subject. After the drop to an I. Q. of 79, the child was given strenuous individual phone drill by a skilled prumary reading teacher with years of experience. At the next exammation the I Q jumped to 98 The drill was stopped for the summer vacation On returning in the Fall the I Q. had dropped to 89 The only explanation presenting itself at present is that the phomic drill (from which he profited at the tıme) $1 \mathrm{~m}$ proved his reading ablity and hence his test performance $\mathrm{He}$ has a splendid physıque, teache 4 credit him with common-sense, good judoement, willingnes 5 and $s 0$ on The $1 \quad Q \quad 79$ and 98 do not warrant the same jrognosis, and there was nothing in the first I $Q$ to lead one to anticipate the second The environment Is median and constant in character Trme and follow-up work, not I Q , will throw light on this case Examination of the eyes 1 eveds no defect of sufficient importance to warlant the character of reading If he had only accommodatingly maintained an I Q of about 60 all would have been well'

Withm the last two year's the Psychological Clinic of the Untversity of Pittsburgh has handled a number of cases going into a very superior institutional home on the cottage plan, and a few cases of children going from very abject conditions into superior private homes In the majority of these eases the institution marks a distinct improvement in intellectual, hygienic, moral and social environment. The accompanying tabulation presents a few such cases from which we have had our first report since the environmental change It will be noted (comparing columns 4 and 10) that $\mathrm{m}$ all the cases except number 2 there is a distinct increase in the rate of gain in mental age following the change in living conditions. The remaining cases hug the lower level of median performance, had poor environmental conditions and are accruing mental months at a much faster rate than before environmental change. There is nothing in the cases just cited which does vio- 
lence to any of the known facts concelning the origin oi coniposition of the data from which the I. Q is derived Such data depend, in the by and large, upon all of the factor's lying back of complex human behavior remainmg relatively constant; in the above cases we have introduced marked change, teaing the child away from famly habits, mores, and influences that sinder o airary laisse zurre conditions might have requined three or four generatrons to effect One may thoroughiy behere in the constancy of the I $Q$ and with perfect consistency refuse to accept statistical trends if there 1 s evidence oi marked departure set i een the first and second test in any one of the factors making up the composite nature of behaviol Any other procedure would be to have the statistical tail wag the causal dog.

Cases transferred from inferior homes to superior institutional life

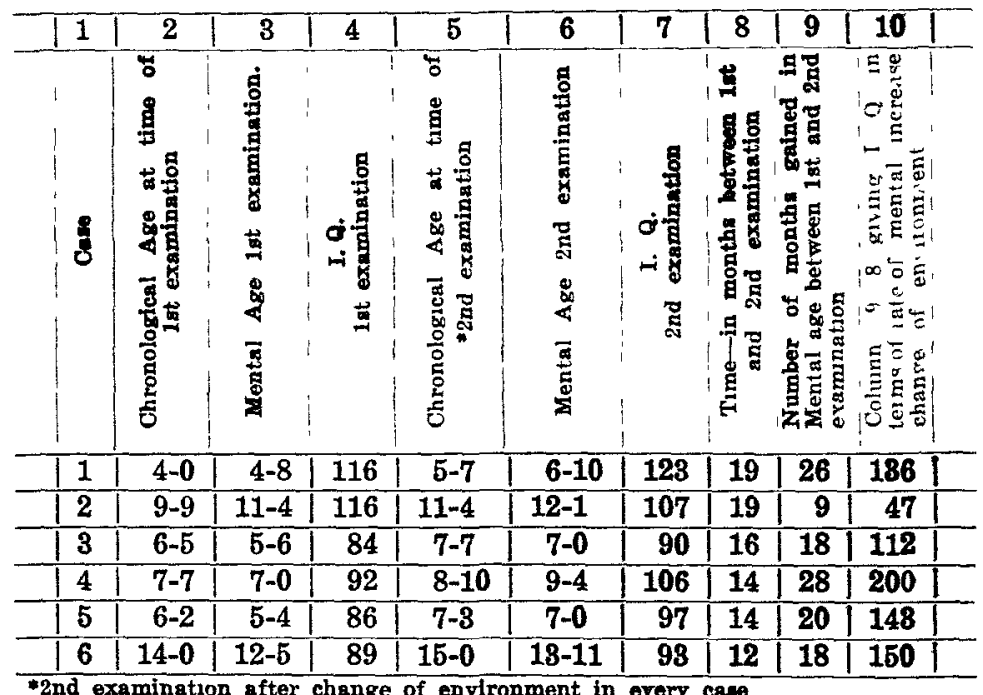

One case more. which the writer had up for consideration recently The subject, a little girl, was eleven years five months old at the time of testing, I Q. 67 (Has had simply unbelievable social conditions Mother and father died of "flu," went with brothe and sister, to live with grandfather and grandmother. Grandmothex died Children then alone with grandfather who is eccentric, morose, grossly ignorant and surly. No companions, and school several miles away ... No shoes, no underwear during winter months. Only a few months schooling . No toys, no outside contacts Squalor and poor food) This child was as timid 
as a deer Although she was almost whout vocabulary, and could not read, hel ability in the Porteus maze tests, HealyFernald construction boards, and her complete lack of the "socalled" stigmata of teeblemindedness pointed towards a diagnosis and prognosis more favorable than the I $Q$ would suggest Now the institution having the child exammed did not want her if feebleminded The matter was finally presented to the institution fiankly stating the dilemma, namely the highly atypical character of the environment Tle institution accepted her At the present moment of writing, she has within a few months acquired sufficient skll to read the passage fiom the Stanford Revision beginning, "New York Sept. 5 , without errol, but still too slowly to score plus

What prognosis should be made" To begin with the case is not quite analogous to the ones cited in the accompanying tabulation, fol in these the $I$ in no case takes the child out of the normal group But may it not be true that the monstrous conditions under which the child has lived has markedly deflated her I. Q ? Is it not possible that if the institution in which she is placed offers hei even median social milieu that the I $Q$ may rise appreciably? The writer would venture the prediction that the subject may attain an adult intelligence of low normal ( $I$ Q of 85 or 90 )

Certain practical applications and suggestions can be made from these two contending viewpoints, statistical trends on the one hand and analysis of the qualitative factors peculiar to an individual case on the other:-

1. Probably no one not even the most enthusiastic euthenist would deny tha, in trends and for school administrative purposes in the large, the resuits of an examination of a school either by the Stanford Revision or a battery of mass tests must be accepted as highly indicative of relative rank-order of the intellectual status of the group studied, and vastly superor to any impressionistic estimate

2. More than this, in the individual case of fluctuation of I. Q. should arouse the attention as to the cause. The first assumption should be that a clerical error in scoring has been made, o1 age has been reported differently at different times. This "hunch" is often correct. (We are assuming trained examiners throughout) Up to this point the burden of proof is with the case that departs markedly from statistical trends. A search for causal factors and an analysis of the nature of the response must now be made. But having verified the accuracy of the data no apology needs be offered to statistical methods; neither is it 
in order for statistical method to offer an apology for fallure in individual conformity.

Statistical method was developed to anticipate trends in data and error therein. At this point in our thinking a quotation from a recent article by Yule' is well worth pondering -

"Statistical methods, I say, should be regarded as ancillary, not essential They are only essential where the subject of investigation is itself an aggregate, as a swarm of atoms, or a crowd. But here (mental measurement) the subject is the indrvidual, not the aggregate of individuals as such. This being the case, statistical methods are only necessary in so far as experiment falls to attain its ideal, the ideal of only permitting one causal circumstance to vary at a time And it should always be the aim of the experimenter not to revel in statistical methods (when he does not revel and swear) but steadily to diminish, by continual improvement of his experimental methods, the necessity for therr use and the influence they have on his conclusions Statistical methods are not only ancllary; they are, to the expermenter, a warning of fallure.

"During the last year or two I have made it a practice to begin a short course of lectures to agricultural students. on some elements of statistical methods, by a lecture devoted entrrely to showing how exceedingly bad agricultural experiments are, how this introduces the necessity for statistical methods in discussing the results, but does not obviate the primary necessity for improving the experimental methods. Is the latter warning unnecessary in the case of experimental psychology? I can only speak as a statistician with an exceedingly limited and sporadic knowledge of what is being done, but it seems to me that it is urgently necessary. The experiment (if it can be called an experiment at all) is often not only bad, but its badness seems to be accepted merely as a rather interesting fact, calling perhaps for the exercise of more elaborate statistical methods a few partial coefficients of correlation a few rather elaborate probable errors . . and that is all. It does not seem to be recognized as primarily a condemnation of the experimenter, perhaps because the experimenter has never been exercised in the sciences where really accurate experiment is possible, so that he has no high ideals before him."

3 Intellectual or emotional repugnance to statistical fatalism has been assigned as one of the reason for objecting to the constancy of the I. Q. I find no reason to believe this to be true of any trained psychologist. The layman and certain schoolmen may

\footnotetext{
'Yule, G Udny Under, "Critıcal Notice," Bi Ji Psych, vol XII, Part 1, June, 1921, page 105 ff
} 
be motivated vaguely by a certain repugnance to anything that undermines the beautiful optimism of,

"I am the captain of my soul,

I am the master of my fate"

but the majority probably do not attempt to think the matter through, or try to orientate intelligence testing in respect to any philisophical basis such as free will or determinism The piactical school man is likely to be an opportunist, and fatalistic finality gives an all of professional expertness, and saves vexatious analysis, trial and error, and suspense

However, while certainly no psychologist would oppose the constancy of the I. Q. for other than scientific reasons, he is most emphatically opposed to any premature statistical finality regarding the whole mattel

There is nothing gained by dealing with statistical results as causally final or chronologically static Statistical stability or variability rests upon causes of such a nature that a rational inquiry into the possibility of modification is irksome, undramatic and may become very vexatious by leading to still greatel causal complexities It is also not a simple matter of "either-or" as regards statictical predictability and stability I read in my morning paper that Los Angeles had over six thousand automobile accidents in 1921 It is safe to predict six thousand for 1922, but it is philosophically bad to resign oneself to the situation A careful analysis of causes could concelvably reduce the death rate Likewise statistics could easily have told us that the death rate In bulding the Panama Canal would have been thus and so, but Goethals did not accept the statistical infertnce but applied preventive medicine and hygiene.

Now turning to intelligence, it is manifestly a behavior composite In our carefully non-selected group in the Standford Rev1sion these is an unbiased sampling of many causal factors of this complex response we call intelligence Let us name some of the probable ones heredity, sensory efficiency or deprivation, social milieu, educational opportunities, glandular secretions, general systemic conditions, disease, nutrition, nature of conditioned reflexes, Freudian complexes, emotional make-up, and so on Immediately it is not likely that any one or a group of these factors will be sufficiently changed, considering the masses, to invalidate the norms of the Stanford Revision. In this sense the age norms are probably temporarily static. It would be bad statistical philosophy, however, acting like an insidious paralysis to all constructive educational advance, if we substituted statistical results for painstaking analysis in a specific case, or for causal analysis for society at large. It is tiue that theie is a wide gulf between 
logically possible modifications of causal factors and the surrogation of these factors into the social habitutations, which condition gives much greater stability to social action and the complex statistical results than the reformer is likely to appreciate. For example, the means is now probably at hand to wipe out tuberculosis if we had the hygenic habits and hygenic morality to back up the sanitary expert

Aside from changes in social habituations, unforseen factors may make marked changes through regulation of glanduler secretions, The cure of cretmns may be followed by the cure of Mongolian idiots Again, greater scientific precision in the education of the baby's conditioned reflexes could conceivably change the intelligence of any particular child, and if instituted on a large scale appreciably raise the median performance or change the intellige:ice rank-order of certain classes of cases

In pedagogical and admistrative problems it is mexcusable to concerve the intelligence norm (namely, the cross-section of the composite set of causal factors) as static The adminıstrator is justified in making subdivisions in classes on the basis of testing but broad constructive pedagogical and adminstrative efforl mu: not cease The teacher should take philosophically the clec.rly demonstrated cases of mental deficiency and not attenut to riake a silk purse out of a sow's ear, to be sure. On the other hand, she should avoid using the I Q. as a blanket excuse, allo.ving it to act like a paralysis to all pedagoical resourcefulness and effort. The low 1. Q. of her class can easily become the perpetual allbi of the poor teacher and a neu form of infant damnation for the pupuls

What the average does may be pretty safe bettin $x$ as to what the average will do under a lansen: farre policy, but it loes not follow at all that it is what the average could or should dc Suppose that by scratching Aladdin's lamp we could reduce the enrollment of every teacher to fifteen pupils, or say correct all glandular infìculties or wipe out all superstition, or secure specifics for areral of the serious chlldren's diseases, would it not only change the median, P E's, and lower limit but might not whole groups change in their relative position in the rank-order of intelligence? Preventive medicine, refinement of social and sanitary habituations, improved methods of handling the emotions, more individualized teaching, and constructive eugenics constitute our only magnc lamr.

Again, sufficient time has not elapsed since the beginning of testing to warrant much prognosis if we are to judge and profit by the vicissitudes of prognosis and cures in medicine.

4. There is considerable evidence from the pathology of the neyvous system that the lower end of the intelligence curve marls the 
intrusion of a distinct set of factors not found thioughout the curve From normal to superior is probably bridged without any change in kind, from normal to feebleminded we have a blending of dull normal with varying degiees of pathological derangement; a e. the entrre curve is distmetly bimodal

This means that preventive medicine or more healthy conditions of conception may remove our worst cases forever This would not - help the pathological cases of to-day to be sure but such a possibilty should make us cautious of statictical estimats of the number of feebleminded we must have Equally true, is wall be fatuous to feel secure for the future on the basis of the present per centage of low grade intelligence Relatively changing birthrates for different classes (all other factors constont) could conceivable shunt the entire intelligence distribution curve. The point is that cogent reasoning and analysis of present and psisible factors and not more abuse of the must over-worked normal distribution curve, will solve our difficulties

5 As ponted out by Stenquist, quite recently, we do not yet know just what a low 1 . Q. means $m$ terms of eventual adjustment in the world And as proof of the tester's diagnosis and prognosin lies far ahead in the future (many times the present age of the Binet Tests, Stanford Revision) it becomes peculiarly easy to make sweeping assertions without any immediate factual check.

6 Finally, there is nothing in the nature of the tests to warrant speaking of them as measuring either heredity or environment separately. Any one is, of course, quite within scientific proprieties, when he offers his opinion as to the dominating iactor in any mental test performance. We must regret, however, that the comniercilazing of the tests has resulted $m$ such unqualified statements as this (appearing in the propectus of a mass test) . ". . . ... is an instrument for the measurment in groups of the native ability of any undividual whether child or adult, who has had the equivalent of three or four years of schooling." 